\title{
Coupled Computational Fluid Dynamics/Multibody Dynamics Method for Wind Turbine Aero-Servo-Elastic Simulation including Drivetrain Dynamics
}

\author{
Y. Li ${ }^{1}$, A. M. Castro ${ }^{1}$, J.E. Martin ${ }^{1}$, T. Sinokrot ${ }^{2}$, W. Prescott ${ }^{2}$, P. M. Carrica ${ }^{1{ }^{1 *}}$ \\ ${ }^{1}$ IIHR-Hydroscience and Engineering, The University of lowa, lowa City, IA 52242, USA. \\ ${ }^{2}$ Siemens Product Lifecycle Management, 2425 Oakdale Boulevard, Coralville, IA 52241, USA. \\ *Corresponding author: pablo-carrica@uiowa.edu, ph 1-319-335-6381.
}

\begin{abstract}
$\underline{\text { Abstract }}$
A high-fidelity simulation framework is presented to investigate wind turbine aero-servo-elastic behavior, coupling dynamic overset computational fluid dynamics (CFD) and multibody dynamics (MBD) approaches. The Gearbox Reliability Collaborative (GRC) project gearbox was up-scaled in size and installed in the NREL 5-MW offshore wind turbine to demonstrate drivetrain dynamics. Generator torque and blade pitch controllers were implemented to simulate operational conditions of commercial wind turbines. Interactions between wind turbulence, rotor aerodynamics, elastic blades, drivetrain dynamics at the gear-level and servo-control dynamics were studied. Results show that gear contact causes dynamic transmission error within the drivetrain, and results in a decreased turbine thrust and rotational speed. The generator torque controller optimizes efficiency below rated wind speed, while the blade pitch controller properly regulates the turbine near rated power and generator speed at higher than rated wind speed under both uniform and turbulent winds. The pitch controller effectively reduces turbine thrust, blade tip deflections, and velocity deficit of the wake, benefiting both standalone turbines and wind farms. The tool and methodology developed show promise to study complex aerodynamic/mechanic systems, being the first time a complete wind turbine simulation includes CFD of the rotor/tower aerodynamics, wind turbulence, elastic blades, gearbox dynamics and feedback control.
\end{abstract}

Keywords: Computational Fluid Dynamics; Multibody Dynamics; Drivetrain Dynamics; Servo-control; Wind Turbulence; Wake Flow 


\section{Introduction}

Renewable energy comprised an estimated $27.7 \%$ of the world's power generating capacity by the end of 2014, among which wind power contributed 370 GW power capacity (with a record single-year increase for 2014 of $51 \mathrm{GW}$ of installed capacity), and 3.1\% of total electricity production [1]. Further increase of wind production share of the energy market depends heavily on the reduction of the levelized cost of electricity (LCOE), through increased performance and reliability. Current trends towards these goals include the use of higher towers, larger rotors, and use of advanced materials and manufacturing techniques for the blades. However, as the length of the blades increases, so does the variability of turbulence experienced by the blades, resulting in larger amplitude changes in load. Besides structural and fatigue issues to the rotor itself, the transmission of large asymmetric rotor loads to the gear system is of interest as it can lead to early drivetrain failure, a major reliability issue for current turbine designs. In this context, the accurate investigation of the coupled aero-servo-elastic behavior of wind turbines in realistic operation provides a promising way to better understand the complex interactions between wind loads and drivetrain dynamics, and as an aid for design and testing of new turbines.

The use of computational fluid dynamics (CFD) for wind turbine applications is becoming attractive as an alternative to more expensive experimental techniques. A distinct advantage of numerical modeling is the possibility of conducting studies at full scale for the complete turbine system, and for complete wind farms. Different levels of complexity for rotor representation are routinely used, from the simpler actuator disk approach to blade element momentum (BEM) representation of the individual blades, to using the fully resolved geometry of the blades. While more computationally intensive, the latter option allows to accurately predict forces and moments over all the turbine structures under unsteady inflow, as well as to predict the transient inflow, wake flow and turbulence, with turbulence and inflow conditions the only modeled components of a simulation. Some examples of use of CFD for wind turbine applications include studies of: wind turbine rotor-tower interaction in full 3D turbine configuration $[2,3]$; wind turbine wake in uniform and turbulent inflows [4]; power production of a wind farm with complex terrain [5]; and a utility-scale offshore wind turbine under incoming wind and waves [6].

Multibody dynamics (MBD) methods provide the capability of simulating complex mechanical and control systems and have been widely adopted into comprehensive wind turbine simulation tools. The interactions between different wind turbine components such as rotor-shaft-gearbox-generator can be naturally addressed using appropriate kinematic constraints or dynamic force elements. MBD is an appropriate alternative to other methods such as Finite Element Method (FEM), more computationally costly, and for which the implementation of multibody constraints is challenging. Some examples of MBD applied to wind turbines are the modeling of the coupled dynamic response of a utility-scale offshore wind turbine including wind inflow, wave field, aerodynamics/hydrodynamics, elasticity and controls of the turbine [7]; the structural optimization of rotor blades [8]; modeling of composite blades with anisotropic material [9]; and study of a complete wind turbine gearbox [10]. 
In this paper, we present a high-fidelity framework for comprehensive utility-scale wind turbine aeroservo-elastic simulations under turbulent wind inflow conditions. This is achieved by coupling of the CFD and MBD approaches, in which the CFD solver predicts the flow field and local forces, and the MBD solver predicts the turbine motions, blade and tower deflections, gear-level loads, and controller state under the aerodynamic loads predicted by the CFD solver. Predicted deformations of the blades are then incorporated to the structured CFD domain, which uses overset technology to provide connectivity between the different grids. Dynamic overset is also used to account for grid motions associated to the rotor yawing and rotation, and active pitching of the blades. Mann's wind turbulence model, recommended by IEC 61400-1 ed. 3 for wind turbine simulations [11], was used to generate inflow atmospheric wind turbulence. Simulations were conducted using the notional NREL 5-MW offshore wind turbine geometry and controller to study the interactions between wind turbulence, rotor aerodynamics, elastic blades, drivetrain and servo-control dynamics. The Gearbox Reliability Collaborative (GRC) project gearbox [12] was up-scaled and adapted for the 5-MW turbine to demonstrate the drivetrain modeling within CFD/MBD framework. Results of the interactions were analyzed in detail with the focus on the influence of the gearbox, generator torque and blade pitch controllers to the turbine and wake flows.

The approach presented is unique as it develops a framework for the fully coupled, high-fidelity simulation of the aerodynamic and drivetrain components of a wind turbine with state of the art methods for each of these components. It allows to isolate and directly investigate the effects of aerodynamic events on the drivetrain, to a detail previously unavailable in the open literature, as well as the effect of modeling choices, such as blade flexibility, turbulence treatment or drivetrain model complexity.

\section{Methodology}

Investigation for aero-servo-elastic behavior of wind turbine operated in realistic conditions is performed using the CFD/MBD/controller coupled approach. The coupling details and validation for the CFD/MBD approach for wind turbine simulations can be found in [13], which focuses on the turbine's aero-elastic behavior in uniform and turbulent winds. Further validation of the CFD solver against experimental data is also available in [14]. Validation of the fully coupled system is not possible due to lack of experimental data available in the open literature, though turbine manufacturers may have access to proprietary data. Turbine manufacturers may also implement the methodology presented herein coupling their own high-fidelity simulations tools. A brief description of the solver components is presented in this section.

\subsection{Flow Solver}

The incompressible CFD code REX is used as the flow solver. Wind turbine aerodynamic prediction capabilities for its predecessor, CFDShip-lowa v4.5, also developed at University of lowa, was validated by extensive comparisons against the Unsteady Aerodynamics Experiment (UAE) NREL Phase VI wind turbine [14], and for the notional NREL 5-WM offshore turbine, for which Mann's atmospheric turbulence model was implemented [13]. 
REX solves the unsteady Reynolds-Averaged Navier-Stokes (URANS) equations, using blended $k-\varepsilon / k-\omega$ modeling for turbulence modeling. Hybrid RANS/LES (Large Eddy Simulation) options are available, using simple methods like DES (detached eddy simulation, [15]), DDES (delayed DES, [16]), and iDDES (improved DDES, [17]). In a previous study [14], it was shown that DES model is able to predict the transient response of wind turbine. In this paper, a DDES model [18] based on Menter's shear stress transport model (SST) [19] is used, to better capture the development of the wake, as the standard DES can over-predict the level of turbulence intensity for more streamlined flows. Single or two-phase flow cases can be considered, allowing simulation of off-shore turbines in waves, with the interface determined using the level set method. Structured body-fitted curvilinear grids are used to represent body geometries; these and any required grids to define the computational domain are connected using an overset approach. Dynamic overset is also used to resolve relative motions and deformations at run time using the code Suggar [20]. The code has shown excellent scalability for large-scale high performance computing applications [21]. Further details regarding the solver and application cases can be found in [21-24] and literature therein.

Non-dimensionalized quantities are used to enforce mass and momentum conservation for incompressible flow with the rotor radius as characteristic length $R$ and prevailing wind velocity as reference velocity $U$.

$$
\begin{aligned}
& \nabla \cdot \boldsymbol{u}=0 \\
& \frac{\partial \boldsymbol{u}}{\partial t}+(\boldsymbol{u}-\dot{\boldsymbol{x}}) \times \nabla \boldsymbol{u}=-\nabla p+\nabla \cdot\left[2\left(\frac{1}{R e}+v_{\mathrm{t}}\right) \nabla^{s} \boldsymbol{u}\right]
\end{aligned}
$$

where $\boldsymbol{u}$ is the fluid velocity; $\boldsymbol{x}$ is the grid velocity accounting for moving or deforming grids; $p$ is the dimensionless piezometric pressure, $p=p_{a b s} / \rho U^{2}+z / F r^{2}+2 k / 3$ with $p_{a b s}$ the absolute pressure, $F r=U / \sqrt{g R}$ is the Froude number, $\rho$ the air density and $k$ the dimensionless turbulent kinetic energy; $R e$ is the Reynolds number $R e=U R / v$, with $v$ the kinematic viscosity; and $v_{\mathrm{t}}$ is the dimensionless turbulent eddy viscosity, as obtained from the turbulence model.

The governing equations for the turbulent kinetic energy $k$ and the specific dissipation rate $\omega$ follow Menter's SST turbulence model

$$
\begin{gathered}
\frac{\partial k}{\partial t}+\nabla \cdot((\boldsymbol{u}-\dot{\boldsymbol{x}}) k)=P_{k}-k^{3 / 2} / l_{D D E S}+\nabla \cdot\left(\left(v+\sigma_{k} v_{\mathrm{t}}\right) \nabla k\right) \\
\frac{\partial \omega}{\partial t}+\nabla \cdot((\boldsymbol{u}-\dot{\boldsymbol{x}}) \omega)=\alpha P_{k} / \nu_{\mathrm{t}}-\beta \omega^{2}+\nabla \cdot\left(\left(v+\sigma_{\omega} v_{\mathrm{t}}\right) \nabla \omega\right) \\
+2\left(1-F_{1}\right) \sigma_{\omega 2} \nabla k \cdot \nabla \omega / \omega
\end{gathered}
$$




$$
v_{\mathrm{t}}=a_{1} k / \max \left(a_{1} \omega, F_{2} S\right)
$$

where $P_{k}=\min \left(v_{t} S^{2}, 10 \beta^{*} \omega k\right), S=\sqrt{2 S_{i j} S_{i j}}$ is the strain rate magnitude,

$S_{i j}=1 / 2\left(\partial u_{i} / \partial x_{j}+\partial u_{j} / \partial x_{i}\right)$. The length scales of the model are

$l_{D D E S}=l_{\text {RANS }}-f_{d} \max \left(0, l_{\text {RANS }}-l_{L E S}\right), l_{\text {RANS }}=\sqrt{k} /\left(\beta^{*} \omega\right)$ and $l_{L E S}=c_{D E S} \Delta$. The DES

constant is computed from $C_{D E S}=C_{D E S 1} F_{1}+C_{D E S 2}\left(1-F_{1}\right)$, with $C_{D E S 1}=0.78$ and

$C_{D E S 2}=0.61$, and $\Delta$ is the grid length scale, taken as the maximum cell side length. $F_{1}$ and $F_{2}$ are the SST blending functions, and $f_{d}$ is an empiric blending function as

$$
\begin{aligned}
& F_{1}=\tanh \left[\left(\min \left(\max \left(\frac{\sqrt{k}}{0.09 \omega \delta}, \frac{1}{\operatorname{Re}} \frac{500}{\delta^{2} \omega}\right), \frac{4 \sigma_{\omega 2} k}{C D_{k \omega} \delta^{2}}\right)\right)^{4}\right] \\
& F_{2}=\tanh \left[\left(\max \left(\frac{2 \sqrt{k}}{0.09 \omega \delta}, \frac{1}{\operatorname{Re}} \frac{500}{\delta^{2} \omega}\right)^{2}\right]\right. \\
& f_{d}=1-\tanh \left(\left(C_{d 1} r_{d}\right)^{C_{d x}}\right), r_{d}=\frac{\mu_{t}+\mu}{\rho \kappa^{2} d_{w \sqrt{0.5\left(S^{2}+\Omega^{2}\right)}}^{2}}
\end{aligned}
$$

where $\delta$ is the distance to the nearest no slip surface and $C D_{k \omega}=\max \left(2 \sigma_{\omega 2} \nabla k \cdot \nabla \omega / \omega ; 10^{-20}\right)$. $\Omega=\sqrt{2 W_{i j} W_{i j}}$ is the vorticity magnitude, $W_{i j}=1 / 2\left(\partial u_{i} / \partial x_{j}-\partial u_{j} / \partial x_{i}\right)$ is the rigid rotational component of the velocity gradient. In Eq. (8) the constants are $C_{d 1}=20, C_{d 2}=3, \kappa=0.41$.

The model constants are $\alpha_{1}=0.31, \beta^{*}=0.09, \alpha_{1}=5 / 9, \beta_{1}=0.075, \sigma_{k_{1}}=0.85, \sigma_{\omega_{1}}=0.5$, $\alpha_{2}=0.44, \beta_{2}=0.0828, \sigma_{k_{2}}=1$ and $\sigma_{\omega_{2}}=0.856 . \alpha, \beta, \sigma_{k}, \sigma_{\omega}$ are computed with the blending function $F_{1}$ as $\alpha=\alpha_{1} F_{1}+\alpha_{2}\left(1-F_{1}\right)$, and similarly for the other constants.

\subsection{Multibody Dynamics Solver}

Virtual.Lab Motion $[25,26]$ is used to simulate structural dynamics of the wind turbine, including blade deformation, as well as gearbox, drivetrain and servo-mechanic dynamics. Both rigid and flexible bodies can be included in the system, with arbitrary translational or rotational displacements. Equations of motions are formulated in the Newton-Euler form using a set of Cartesian generalized coordinates that locate and orient the center of mass of each body in an inertial reference frame. The generalized coordinates consist of the translational $\mathrm{X}, \mathrm{Y}$, and $\mathrm{Z}$ of each body's center of gravity and a quaternion of the Euler parameters $\left(e_{0}, e_{1}, e_{2}, e_{3}\right)$ are used to orient the center of gravity reference frame. Simulated bodies are connected by force and joint elements, describing kinematic and dynamic constraints. 
Constraints and the equations of motions are formally written as a set of differential-algebraic equations (DAEs). The kinematic constraints $\boldsymbol{\phi}$ are expressed algebraically by

$$
\phi(q, \mathrm{t})=0
$$

where $\mathbf{q}=\left[\mathbf{q}^{1} \mathbf{q}^{2} \ldots \mathbf{q}^{n}\right]^{T}$ is the vector of the generalized coordinates (translational and rotational) of each of the $n$ bodies in the global frame of reference. The equations of motion for each body $i$ is written as

$$
\boldsymbol{M}^{i} \ddot{\mathbf{q}}^{i}+\boldsymbol{\phi}_{q_{\mathrm{i}}}^{T} \lambda=Q_{v}^{i}+Q_{\mathrm{B}}^{i}
$$

where $\boldsymbol{\phi}_{q_{\bar{i}}}^{T}$ is the transpose of the Jacobian of the vector of constraints $\boldsymbol{\phi}$ with respect to the generalized coordinates of the body $i$, and $\lambda$ is the vector of the Lagrange multipliers used to append

the kinematic constraints to the equations of motion. $\boldsymbol{M}^{i}$ is the mass matrix, $\boldsymbol{Q}_{v}^{i}$ is the quadratic velocity vector used to describe non-inertial forces (Coriolis and centrifugal terms); $\boldsymbol{Q}_{e}^{i}$ is the vector of external applied forces, in the present application the loads obtained from CFD solver for the wind turbine simulation. The flexibility in the blade and tower models are defined by a lumped mass approach where the blade is subdivided into separate bodies connected by a beam force element. Therefore, the vector $Q_{e}^{i}$ also includes the gravity force and beam forces between bodies. The combination of equations Eq. (9) and Eq. (10) form a set of DAEs that must be solved at every time step.

\section{Specification of Simulated Cases}

This section discusses turbine geometry and material properties, control system, drivetrain, CFD grids and MBD components. A summary of the conditions simulated is also presented.

\subsection{Wind Turbine}

The conceptual NREL 5-MW offshore wind turbine $[27,28]$ is used in the present study. The three-bladed turbine has a rotor diameter of $126 \mathrm{~m}$ and the hub height is $90 \mathrm{~m}$; the tilt angle of $5^{\circ}$ and precone angle of $2.5^{\circ}$ are comparable to those of commercial turbines. The turbine uses conventional variable speed and pitch controls. Rated conditions for the turbine are wind speed of $11.4 \mathrm{~m} / \mathrm{s}$ and rotor speed of 12.1 RPM. Rated tip speed results in a moderate Mach number $(M \approx 0.23)$ that allows for the use of an incompressible fluid flow solver. 


\subsection{Wind Turbine Control System}

A conventional variable speed, variable blade pitch wind turbine control system based on the offshore code comparison collaboration project (OC3) [27] was implemented in the CFD/MBD framework, consisting of a generator torque controller and a full-span rotor-collective blade pitch controller operating independently at different wind turbine operational conditions.

Figure 1 shows a schematic of the control system. Depending on the generator speed, the wind turbine operation is categorized in 5 different regions. The generator torque controller is used for operation below the rated conditions of wind speed $11.4 \mathrm{~m} / \mathrm{s}$ and generator speed 1173.7 RPM. In region 1 below cut-in wind speed, the wind power is used to accelerate the rotor for the turbine start-up, and therefore the generator torque is zero with no power extracted from the wind. Region $1 \frac{1}{2}$ is a linear transition between the start-up and region 2, placing a lower limit of the generator speed for wind turbine's operational speed range. Region 2 is designed for the turbine to best capture the wind power, and the generator torque is proportional to the square of the generator speed, maintaining a constant optimal tip-speed ratio ("optimal torque" curve in Fig. 1(a)). The optimal constant of proportionality as reported in [27] is $0.0255764 \mathrm{~N} \mathrm{~m} / \mathrm{rpm}^{2}$. The linear transition region $2 \frac{1}{2}$ is needed to limit tip speed at rated power. In region 3 beyond the rated condition, constant power is sought, resulting in a generator torque inversely proportional to the generator speed.

The full-span rotor-collective blade pitch controller is constructed with a gain-scheduled proportionalintegral (PI) controller on the speed error between the actual generator speed and the rated generator speed (1173.7 RPM), as shown in Fig 1(b). The relationship of the change of the pitch angle and the speed error can be written as [27]

$$
\Delta \theta=K_{p} \Delta \Omega+K_{I} \int_{0}^{t} \Delta \Omega \mathrm{dt}
$$

where $\Delta \theta$ is a change of the blade pitch angle in radians, $\Delta \Omega=\Omega_{\text {current }}-\Omega_{\text {rated }}$ is the generator speed error, of which $\Omega_{\text {rated }}=122.91 \mathrm{rad} / \mathrm{s}$ is the design rated generator speed and $\Omega_{\text {current }}$ is the generator speed at current time step, $K_{p}$ and $\mathrm{K}_{I}$ are the controller's proportional and integral gains, respectively.

$$
\begin{aligned}
& K_{p}=K_{p_{2} 0} \times G K(\theta) \\
& K_{I}=K_{I_{2} 0} \times G K(\theta) \\
& G K(\theta)=\left(1+\theta / \theta_{K}\right)^{-1}
\end{aligned}
$$

where $K_{P_{\ell} 0}=0.01882681 \mathrm{~s}, K_{I, 0}=0.008068634$ and $\theta_{K}=0.109988412 \mathrm{rad}$ are the appropriate controller constants for the turbine. $G K(\theta)$ is the dimensionless gain-correction factor, and 
$\theta$ is the current blade pitch angle. The blade pitch actuator is subject to a maximum pitch rate of 8 $\mathrm{deg} / \mathrm{s}$.

While not currently implemented, the built-in controller routines can be replaced by calls to dynamically linked objects (.dll in Windows, .so in Linux) if needed, allowing the use of proprietary controller libraries within the solver, even if the source code is not distributable.

\subsection{Drivetrain}

Figure 2 shows the overall configuration for the drivetrain. Due to limited details of the conceptual NREL $5-\mathrm{MW}$ offshore wind turbine drivetrain, and the unavailability of a utility-scale wind turbine drivetrain for numerical modeling, a representative 3-point suspension drivetrain configuration from the Gearbox Reliability Collaborative project (GRC) [12] is adopted and tuned to match the 5-MW turbine. The original GRC drivetrain has a $750 \mathrm{~kW}$ rating and an overall gear ratio of 1:81.491. The gearbox has one planetary stage (low speed stage), and two parallel stages as intermediate stage and high speed stage. Three planetary gears are equally spaced around the sun gear, and supported by the planet carrier which distributes the torsional loads among the planets from the main shaft. The properties of the shafts and gearbox were then adapted to match the drivetrain properties of the 5-MW turbine, as summarized in Table 1.

Drivetrain components, e.g. shafts and gears, are represented by 6-DOFs rigid bodies, with appropriate kinematic constraints and dynamic force elements to describe their connections. Different levels of modeling complexity can be considered. The simplest modeling approach is the 2-DOFs rotor-generator torsional model, constructed by revolute joints for shafts and kinematic constraints within gearbox for the design gear ratio in the multibody model system; bracket joints constraining relative motions are used between the connected shafts. Though simple, this model enables the implementation of the wind turbine control system, which requires interaction between rotor and generator. An improved model adds a 3-stage gearbox model that includes gear contact force elements and is capable of estimating physical multi-tooth contact, changes in the direction of gear rotation, and gear-level loads. These two approaches are used on this work. A further refinement of the model that has been implemented adds bearing representation with a radial bushing force element and enables all DOFs in the plane of rotation for shafts and gears. This allows for more realistic estimation of the drivetrain dynamics, including shaft misalignment due to transient loads caused by wind gusts or turbulence, non-torque loadings due to asymmetric rotor loads, and bearing and gear-level loads.

The control system described is implemented in the MBD solver. When the turbine is operated below the rated condition, the generator torque controller applies torque as a function of the generator speed on the high speed shaft (HSS), which is rigidly connected to the generator, such that the rotor speed is regulated with the purpose of obtaining the best efficiency. For turbine operated beyond the rated condition (region 3 ), the blade pitch controller applies controlled torque on the revolute joints connecting the individual blades to the hub. The change of the pitch angle is executed by applying the corresponding torque on the rotational spring-damper element of the blade revolute joint. 


\subsection{Multibody System Model}

The multibody system consists of 6 components for the turbine ( 3 blades, hub, nacelle and tower) linked by appropriate kinematic constraints at their interface. Connection between the blades and the hub is implemented with a bracket joint for fixed blade pitch, or revolute joint with rotational spring-damper element for active pitch control. Revolute joints are used between the hub and nacelle along the rotational axis of the rotor, and between the nacelle and tower along the yaw axis to allow rotor rotation and yaw motion while constraining other DOFs. Multiple rigid bodies are used to define the tower and the blades. Bracket joints are used for rigid simulation and beam force elements are used for flexible turbine simulation to allow 6 DOFs of each body. Structural properties of the components include mass and center of gravity, sectional stiffness and inertia as defined in $[27,28]$. In total the turbine system has 157 bodies, including 48 bodies for each blade/tip, 11 bodies for the tower, and 1 body each for nacelle and hub.

The coupled CFD/MBD approach resolves motion of all the turbine components except for the drivetrain, which is modelled in the MBD system only. As shown in Fig. 2, the drivetrain's low speed shaft (LSS) is rigidly connected to the hub, the motion of which serves as boundary conditions for this drivetrain component. With this design, interaction between the rotor and drivetrain can thus be communicated through the LSS.

\subsection{CFD Grid Design}

The grid system used for CFD is shown in Fig. 3, consisting of body-fitted curvilinear grids for the turbine components and Cartesian grids to refine the solution in certain zones of interest and for the background. Grids are generated using Pointwise GridgenV15. Volumetric grids originating on complex solid surfaces such as the blades are generated from elliptic surface grids using a hyperbolic solver, with expansion parameters typically in the range 1.15 to 1.2. For solids of revolution, such as the tower or the hub, a hyperbolic solver is used to create a surface grid with similar expansion parameters, and the final grid is generated by rotating this surface about the axis of the body. Cartesian grids for refinements and background are designed to match the element size of the outer layers of body-fitted grids. The overset solver stitches the grids by matching as much as possible the element sizes of the donor and interpolated cells, thus the quality of the final grid can be checked prior to the solution of the aerodynamic problem. Expansion ratios of up to 2 are used for the background in the last few points in the far field to minimize the interaction of the boundary conditions with the solution of the regions of interest. A total of $6.7 \mathrm{M}$ grid points were used. Accurate representation of the blades and the tower as documented in $[27,28]$ was used, while an approximate geometry was used for the hub and nacelle with reasonable dimensions, since the specifications of the OC3 turbine do not include geometric information for these components. The background grid is extended several radii in the vertical and lateral directions, to minimize boundary and blockage effects. The grid spacing is designed to be finer than those of the Mann's box used to set the inlet condition, to properly capture the wind turbulence generated by the explicit wind turbulence model. Three rotating Cartesian blade refinement grids are implemented solidary to the body-fitted blade grids. A fixed wake refinement is also included. Dimensions for the grids are included in Table 2. 
No-slip boundary conditions are set for all solid surfaces. The grid spacing at the wall is designed to satisfy the condition of $y^{+} \leq 1$ as required by the turbulence model. Inlet boundary conditions impose flow velocities for uniform and turbulent wind (Dirichlet boundary condition); zero second-derivative is imposed on the velocity at the exit boundary; and zero-gradient boundary conditions are applied on the top and lateral boundaries. An immersed no-slip boundary is imposed at the still water level for the offshore turbine.

The turbine motions are predicted within the CFD/MBD framework, including rotor rotation, turbine yawing, active blade pitching as well as the floating motion for offshore turbine. For this work only rotor angle and blade pitch are considered. Dynamic overset is then used to compute the domain connectivity information between the different grids to account for their relative motion, and thus providing all the necessary information for the CFD calculation.

\subsection{Simulated Cases}

Cases presented in this paper were designed with an increasing level of complexity to demonstrate different aspects of the implemented wind turbine dynamic modeling with drivetrain (as summarized in Table 3). For all simulations, the same Mann's wind turbulence model parameters as those in [13] were used, with a medium turbulence intensity $14 \%$ (wind turbine class B), and a dimensionless shear distortion parameter 3.9 to account for anisotropic turbulence. Only zero-yaw motion was considered. Agreement of results in [13] with those available from the OC3 initiative was good, and no further validation of the code is provided herein.

Case set 1 was designed to investigate the effect of gear contact. A moderate wind speed of $8 \mathrm{~m} / \mathrm{s}$ was used with the controller disabled. A constant torque resistance $(20 \mathrm{kN} \times \mathrm{m})$ was applied to the generator side; this value was selected from the available results from OC3 $[13,27]$ as representative of torque for this wind condition.. For the current simulation the rotational speed was free to vary, and the rotor adjusted its speed in balance with the prescribed generator torque.

The generator torque controller was tested in case set 2 for a rigid turbine at a wind speed of $8 \mathrm{~m} / \mathrm{s}$, which is in the optimal operation region of the turbine. The blade pitch was fixed at the design value of zero degrees while the rotor speed was regulated by the controller.

The collective blade pitch controller was demonstrated in case set 3 under a wind speed of $18 \mathrm{~m} / \mathrm{s}$. The condition greatly exceeds rated speed, thus the turbine was operated in region 3 . Four reference cases (cases 3.1 to 3.4) were included for both rigid and flexible blades with the controller disabled. The rated rotor speed of 12.1 RPM and design blade pitch angle of zero degree were set for these

reference cases. For the cases with the blade pitch controller enabled (cases 3.5 to 3.7), the blade pitch changed dynamically due to the controller actions seeking to maintain the rated power, while the rotor speed reacted as a consequence of the interaction between the wind, rotor, drivetrain and the controller. 


\section{Results and Discussion}

Results for the three different case sets previously defined are presented and discussed in the context of gear contact effects and controller effects.

\subsection{Effect of gear contact}

The effect of gear contact is quantified by the dynamic transmission error (DTE). DTE is an important parameter of the drivetrain operation and a main source for noise and vibration of a geared system. The dynamic transmission error along the line of action is defined as DTE $=r_{b 1} \theta_{1}-r_{b 2} \theta_{2}$ for a gear pair, where $\theta_{1}$ and $\theta_{2}$ are the rotational angles of the driving and driven gear, respectively. $r_{b 1}$ and $r_{b 2}$ are the base circle radii of the gears.

Case set 1 results comprise four conditions, which include all possible combinations of considering turbulent fluctuations in the incoming wind and the use of the 3-stage gearbox model. Being a more realistic model, the 3-stage gearbox model predicts the DTE, which is zero in the simpler 2-DOFs rotorgenerator torsional model of the drivetrain.

Gear contact effects are first considered for uniform incoming wind conditions. The gear contact effect is shown in Fig. 4. An average $0.256 \mathrm{~mm}$ transmission error exists between the intermediate speed shaft (ISS) and high speed shaft (HSS) gear pair for the turbine with gear contact, with fluctuations caused by the external tower shadow and internal gear stages. Transmission errors from all gear pairs within the gearbox lead to variation of the gear ratio, fluctuating within $0.02 \%$ of the design value of 97 .

Though the variation due to transmission error seems small, it causes noticeable changes to the turbine behavior and performance as shown in Fig. 5 . While the HSS torque for no gear contact averages the imposed generator torque, the HSS torque considering gear contact exhibits much larger fluctuations and higher mean value due to the transmission error. Consistently, a lower HSS speed $(-0.4 \%)$ is observed, with higher frequency fluctuations. The rotor speed behaves similarly, leading to higher rotor torque and lower rotational speed for the case considering gear contact (see Table 4 case set 1 for a quantitative summary). The rotor thrust is also smaller for the gear contact case. The turbine mechanical power is slightly smaller for the gear contact case $(-0.2 \%$, compared to $-0.4 \%$ decreases in RPM and thrust) than for the no contact case.

Inclusion of turbulent fluctuations provides no further insight regarding gear contact conditions as overall follows similar trends as those observed for uniform wind. While a different operational point is reached, with higher rotational speed and rotor thrust, and lower power with respect to uniform wind conditions, and tenfold increase on fluctuation amplitude for all quantities, the changes between contact and no contact gear conditions are consistent for both wind condition simulations.

The spectrum analysis in Fig. 6 shows quantities of interest in the frequency domain, which are important for fatigue and reliability analyses of rotor and drivetrain. Inclusion of turbulent fluctuations in the flow field increase energy levels at all frequencies, and masks the dynamic response of the 
system, therefore more of the following discussion focuses on uniform wind conditions. Spectra exhibit peaks at around $0.45 \mathrm{~Hz}$, corresponding to the blade passage frequency (three times the rotor rotation frequency), essentially showing the effect of individual blades passing by the tower. Lower frequencies have greater influence on power and thrust, as expected when considering the large rotor inertia. Gear contact shows little effect on both rotor and high speed shaft rotation. On the other hand, these low frequency excitations have important influence on the gear loads, as shown by the peaks for the gear contact forces below $2.5 \mathrm{~Hz}$. The gear contact forces show a primary peak at $3 \mathrm{~Hz}$ for both uniform and

turbulent winds, indicating a characteristic frequency of the drivetrain caused by the elasticity of the low speed shaft. It is possible to trigger resonant vibrations with external loads for this relatively low frequency, in particular by broadband excitations produced by turbulence. Note that because only torsional DOFs are allowed for the drivetrain components, the two gear contact forces essentially show the same pattern as the torque being transmitted from the main shaft along the drivetrain components.

\subsection{Effect of generator torque controller}

Case set 2 is equivalent to the previous set in external wind conditions, but the defined generator torque controller is used instead of imposing the generator torque. The controller seeks to maximize power by optimizing the blade tip speed ratio, and regulates to an averaged rotor speed of approximately 9.2 RPM at this moderate wind of $8 \mathrm{~m} / \mathrm{s}$, resulting in a tip speed ratio of 7.6. The applied generator torque varies with the change of the generator speed, with values higher than the constant generator torque of $20 \mathrm{kN} \cdot \mathrm{m}$ applied for case set 1 , resulting in a larger transmission error between the drivetrain gear pairs. The power remains at $1.9 \mathrm{MW}$ in average, with slower rotor speed and thus smaller tip speed ratio. As a consequence, the thrust decreases due to a slower rotor speed, relieving blade stresses. Movies S1 and S2 (available online) demonstrate the effect of the generator torque controller in turbulent winds with the focus on turbine performance (Movie S1) and drivetrain behavior (Movie S2). The fluctuations in gear contact forces caused by wind turbulence are reduced by using the torque controller, as the tip speed ratio is closer to constant and the turbulent loads decrease; in addition, the average power increases in almost 1\% (see cases 2.1 and 2.2 in Table 4), compared to a reduction of $3 \%$ (cases 1.1 and 1.2) when turbulence is included without a controller. Similar to case set 1 , it is also shown that drivetrain has the effect of reducing thrust with a slower rotor speed.

Comparing power spectra in Figs. 6 and 7, control of the generator torque to the HSS introduces additional excitations at higher frequencies, as can be seen from the HSS speed and gear contact forces. Similar to case set 1 , there is a primary peak for the gear loads at $3 \mathrm{~Hz}$ in both uniform and turbulent winds, indicating that this is a characteristic frequency of the drivetrain. Regarding the responses in lower frequency, more frequency content is present respect to the cases without controller, and thus may cause more concerns on blade fatigue by the fluctuating loads. It is also clear the important influence of the tower shadow on the rotor, with the primary peaks occurring at about $0.45 \mathrm{~Hz}$ and higher harmonics. 


\subsection{Effect of blade pitch controller}

As discussed earlier, at wind speeds above the rated speed the turbine switches to constant power operation using pitch control. Note that a positive pitch angle is defined with the trailing edge pointing downwind. Figure 8 shows variables of interest for the turbine operated at wind speed of $18 \mathrm{~m} / \mathrm{s}$, about $60 \%$ higher than rated. As can be seen in Fig. 8 and Table 4 (case set 3), the mechanical power at this high wind averages the target rated value of 5.3 MW, while the rotor speed is maintained well within the rated value of 12.1 RPM. For the uniform wind cases, the controller shows excellent capability of achieving its control objective with small fluctuations. For turbulent wind, for which the wind speed at hub height can be as high as the cut-out speed of $25 \mathrm{~m} / \mathrm{s}$, the controller performs fairly well but shows high amplitude fluctuations. This is due to the intrinsic dynamics of the controller and actuators, which cannot follow high-frequencies due to imposed limitations in the controller. Note that the turbine thrust is well within $400 \mathrm{kN}$ for all cases, a better performance than the moderate wind cases without the blade pitch controller (see case sets 1 and 2 in Table 4). This is a desirable consequence to having a blade pitch controller for stand-alone turbines, for which loads are reduced, as well as also for groups of turbines in a wind farm for which the velocity deficit is reduced, resulting in a weaker wake.

As the blade pitch angle is dynamically regulated, the average pitch angle in uniform wind reaches approximately 14 degrees for the turbine with flexible blades and 14.6 degrees for rigid blades, while the turbine with flexible blades in turbulent wind sees pitch variations between 13.5 and 15.8 degrees (a supplementary Movie S3 shows the blade pitch controller in action for a flexible blade turbine in turbulent wind with mean wind speed of $18 \mathrm{~m} / \mathrm{s}$ ). The blade pitch angle exhibits small periodic variations in uniform wind due to tower and tilt effects, increasing the pitch angle and thus decreasing the angle of attack when blade is approaching the tower from top to bottom, and decreasing the pitch angle from bottom to top when the blade moves away from the tower. Table 4 also shows results for the wind turbine with the controller disabled at high winds. This scenario leads to much larger thrust and torque, and therefore places the turbine in a dangerous operational condition of damaging the drivetrain and blades due to large off-design torsional and rotor loads.

Figure 9 shows frequency spectra of rotor power, thrust, blade pitch, gear contact force, and rotor and HSS speed. As was the case with the moderate wind cases, the tower's shadow shows its influence on power at the blade passage frequency of about $0.6 \mathrm{~Hz}$ and higher harmonics, but in contrast, the energy content tends to be distributed evenly for the three main harmonics due to the blade pitch controller. Also note that the blade elasticity has the effect of mitigating the gear loads as shown in Fig. 9 for the gear contact forces at HSS, but it also introduces additional frequency response in the low frequency range. Comparing with the HSS speed spectrum without controller in Fig. 6 and with generator torque controller in Fig. 7, the blade pitch controller significantly amplifies the amplitude of the peaks and induces more frequency content in the low frequency range due to the large rotor inertia and slow rate 
of change of the blade pitch (as determined by the controller, including the pitch rate limit of $8 \mathrm{deg} / \mathrm{s}$ ) shown in the blade pitch spectrum.

Figure 10 compares blade tip deflections for the high wind condition of $18 \mathrm{~m} / \mathrm{s}$. The deflections are respect to the coned coordinate system that rotates with the rigid rotor. Positive out-of-plane (OoP) deflection points downwind in the coned coordinate system, positive in-plane (IP) deflection points from leading edge to trailing edge, opposite to the blade rotational direction. Due to the rotational and tilt effects, all blade deflections exhibit cyclic oscillations. The tower shadow influence remains an important factor to increasing the blade-tower clearance for a turbine operating with a blade pitch controller. When the controller is enabled, as for typical utility-scale turbines, averaged OoP deflections in both uniform and turbulent winds are reduced by a factor of 4 to $1.9 \mathrm{~m}$, compared with the $7.7 \mathrm{~m}$ deflection observed for a turbine without a controller and at constant zero pitch, and thus contributing to reduce risks of structural damage while producing high power. This is expected, since the controller executes the pitch blade to significantly reduce the turbine power and torque (see Table 4 and Movie S3). For IP deflection, the high wind further pushes it towards the leading edge, and the blade pitch controller contributes to mitigate these trends by increasing the pitch angle, with the consequent higher stiffness in the IP direction and already discussed load release.

As previously mentioned, a beneficial consequence of an active blade pitch controller is a decreased velocity deficit in the wake, as shown in Figs. 11 and 12 for a wind speed of $18 \mathrm{~m} / \mathrm{s}$. Figure 11 shows a horizontal cross section colored with instantaneous dimensionless axial velocity at an elevation $z=60 \mathrm{~m}$ at the end of the $10^{\text {th }}$ rotation. The location of the cross section corresponds to the instantaneous location of the mid-span of blade 1. When the turbine is operating in uniform wind at zero degree pitch and without controller, the momentum loss on the blades and tips are clearly visible, with the resulting significant velocity deficit on the wake to the end of the simulation domain 5-radii $(315 \mathrm{~m})$ downstream of the tower. With a blade pitch controller, the blade tip deflections are dramatically reduced due to the much smaller thrust. The velocity deficit on the wake is also reduced significantly with much less influence from the rotating blades, and the main contribution is from the tower shadow. Note that tower-induced velocity deficit tends to be asymmetric, resulting from the rotor-induced angular swirl. The pitch controller shows similar influence for the turbine operating in turbulent wind, effectively reducing blade deflections and velocity deficit of the wake. The power control by reducing the angle of attack is beneficial to wind turbine and farm operation, as opposed to control by stalling the flow on the blades, which reduces the power at the cost of increased stress and higher velocity deficit on the wake. Movie S4 demonstrates the influence of blade pitch controller on wake flows with the flexible turbine operating in uniform wind at high wind speed of $18 \mathrm{~m} / \mathrm{s}$.

Figure 12 shows average axial velocity profiles on the wake at different axial positions for a horizontal line located at $z=60 \mathrm{~m}$. The velocities were obtained averaging the last 5 rotor rotations. The cases without controller show dimensionless axial velocities varying from 0.7 to 1 across lateral positions, 
while the cases with controller enabled exhibit axial velocities ranging from 0.85 to 1 . The width of the wake is similar for the cases with and without pitch controller, but the velocity deficit is a factor of 3 higher for the cases without controller. As expected due to additional diffusion, the cases with wind turbulence show a wider wake but still the width is similar with and without active pitch control. The case without controller also shows that the tower wake has moved sidewise three times more than the pitch-controlled case, evidencing a much stronger tangential induction factor when the controller is disabled, again consistent with a higher axial induction factor reflected in a stronger wake. This analysis of wake flow is relevant in that it could provide valuable information for turbine placement in wind farms.

\section{Conclusions and Future Work}

In this paper, a framework for wind turbine aero-servo-elastic simulation was presented, incorporating a multibody drivetrain model and control systems into a high fidelity coupled CFD/MBD simulation tool. This approach enables capabilities to investigate interaction between turbulent wind, rotor aerodynamics, elastic blades, drivetrain dynamics at the gear-level and servo-control dynamics. Several simulations of increasing complexity were performed with the conceptual NREL 5-MW offshore wind turbine to test and demonstrate the implemented models.

The effect of gear contact involving dynamic transmission error was shown for a case with constant generator torque in a moderate wind, resulting in a decreased thrust and rotational speed on the turbine. As expected, the drivetrain influence on the rotor behavior is shown to be present independent of incoming wind conditions and controller type. As shown in previous studies, the tower shadow has also been found to have consistent and considerable effect on the rotor's aero-elastic behavior, wake flow, and as this paper shows also on drivetrain dynamics. The use of a generator torque controller helps to improve the power efficiency and reduce thrust, at the cost of inducing excitations at higher frequencies but with minimal influence on the gear loads. This can be observed from the spectrum analysis, where which shows that high frequency fluctuations attributed to the drivetrain dynamics are observed on the rotor when the controller is enabled, while they have only minimal influence on the rotor when the controller is not used. The controller is also able to reduce mean fluctuations of rotor quantities such as thrust and rotor speed caused by turbulent winds, to magnitudes comparable to uniform wind conditions. Wind turbulence was shown to significantly increase the gear loads, independent of the generator torque controller. The blade pitch controller efficiently regulates the turbine to maintain the constant rated power and generator speed under high winds for both uniform and turbulent inflows, which also is useful in reducing thrust, a great benefit for both stand-alone turbines and wind farms in terms of blade deflections and loads, and turbine performance. In addition, the wake study demonstrated the benefit and need of using an active-pitching control mechanism over the stall-regulated strategy for wind farms, leading to a decreased and more uniformly distributed wake even under turbulent wind conditions. The technique also opens the possibility to quantitatively investigate turbine placement in wind farms for optimized power production under complex operational environments. 
Future work will focus on the development and implementation of a farm simulation tool scalable to hundreds of turbines, with the goal of studying farm power production optimization and drivetrain stress minimization. Improvements to the model of the drivetrain are also considered as future work.

\section{Acknowledgements}

This research was supported by IAWIND (Grant IOEI 188570301) under project "Tool Development for Direct Simulation of Interaction between Aerodynamic and Gearbox Loads," and the National Science Foundation Energy for Sustainability Program under grant 1066627, Dr. Ram Gupta program manager. Computations were performed in Helium, the high performance computing resource at the University of lowa.

\section{References}

[1] REN21. Renewables 2015 global status report. Paris: REN21 Secretariat; 2015.

[2] Zahle F, Sørensen NN, Johansen J. Wind turbine rotor-tower interaction using an incompressible overset grid method. Wind Energy 2009;12:594-619. doi:10.1002/we.327.

[3] Hsu M-C, Akkerman I, Bazilevs Y. Finite element simulation of wind turbine aerodynamics: validation study using NREL Phase VI experiment. Wind Energy 2013:461-81. doi:10.1002/we.1599.

[4] Troldborg N, Zahle F, Réthoré P-E, Sørensen NN. Comparison of wind turbine wake properties in non-sheared inflow predicted by different computational fluid dynamics rotor models. Wind Energy 2014. doi:10.1002/we.1757.

[5] Politis ES, Prospathopoulos J, Cabezon D, Hansen KS, Chaviaropoulos PK, Barthelmie RJ. Modeling wake effects in large wind farms in complex terrain: the problem, the methods and the issues. Wind Energy 2012;15:161-82. doi:10.1002/we.481.

[6] Quallen S, Xing T, Carrica PM, Li Y, Xu J. CFD simulation of a floating offshore wind turbine system using a quasi-static crowfoot mooring-line model. Journal of Ocean and Wind Energy, Transactions of the ISOPE 2014;1:143-52.

[7] Vorpahl F, Strobel M, Jonkman JM, Larsen TJ, Passon P, Nichols J. Verification of aero-elastic offshore wind turbine design codes under IEA Wind Task XXIII. Wind Energy 2014;17:519-47. doi:10.1002/we.1588.

[8] Bottasso CL, Campagnolo F, Croce A, Dilli S, Gualdoni F, Nielsen MB. Structural optimization of wind turbine rotor blades by multilevel sectional/multibody/3D-FEM analysis. Multibody System Dynamics 2014;32:87-116. doi:10.1007/s11044-013-9394-3.

[9] Kim T, Hansen AM, Branner K. Development of an anisotropic beam finite element for composite wind turbine blades in multibody system. Renewable Energy 2013;59:172-83. doi:10.1016/j.renene.2013.03.033.

[10] Helsen J, Vanhollebeke F, Marrant B, Vandepitte D, Desmet W. Multibody modelling of varying complexity for modal behaviour analysis of wind turbine gearboxes. Renewable Energy 2011;36:3098-113. doi:10.1016/j.renene.2011.03.023. 
[11] International Electrotechnical Committee. IEC 61400-1: Wind turbines part 1: Design requirements. International Electrotechnical Commission; 2005.

[12] Link H, LaCava W, Van Dam J, McNiff B, Sheng S, Wallen R, et al. Gearbox reliability collaborative project report: findings from phase 1 and phase 2 testing. NREL/TP-5000-51885. National Renewable Energy Laboratory; 2011.

[13] Li Y, Castro AM, Sinokrot T, Prescott W, Carrica PM. Coupled multi-body dynamics and CFD for wind turbine simulation including explicit wind turbulence. Renewable Energy 2015;76:338-61. doi:10.1016/j.renene.2014.11.014.

[14] Li Y, Paik K-J, Xing T, Carrica PM. Dynamic overset CFD simulations of wind turbine aerodynamics. Renewable Energy 2012;37:285-98. doi:10.1016/j.renene.2011.06.029.

[15] Shur M, Spalart PR, Strelets M. Detached-eddy simulation of an airfoil at high angle of attack, in: Engineering Turbulence Modelling and Experiments 4, Elsevier, 1999; 669-678. doi:10.1016/B978-008043328-8/50064-3.

[16] Spalart PR, Deck S, Shur M, Squires KD, Strelets MK, Travin A. A New Version of Detached-eddy Simulation, Resistant to Ambiguous Grid Densities, Theoretical and Computational Fluid Dynamics 2006; 20: 181-195. doi:10.1007/s00162-006-0015-0.

[17] Shur M, Spalart PR, Strelets MK, Travin A. A hybrid RANS-LES approach with delayed-DES and wallmodelled LES capabilities, International Journal of Heat and Fluid Flow 2008; 29: 1638-1649. doi:10.1016/j.ijheatfluidflow.2008.07.001.

[18] Gritskevich MS, Garbaruk AV, Schütze J, Menter FR. Development of DDES and IDDES formulations for the $k-\omega$ shear stress transport model. Flow, Turbulence and Combustion 2011;88:431-49. doi:10.1007/s10494-011-9378-4.

[19] Menter FR. Two-equation eddy-viscosity turbulence models for engineering applications. AIAA Journal 1994;32:1598-605. doi:10.2514/3.12149.

[20] Noack RW. SUGGAR: a general capability for moving body overset grid assembly. In: 17th AIAA computational fluid dynamics conference, Toronto, Ontario, Canada; 2005. doi:10.2514/6.20055117.

[21] Carrica PM, Huang J, Noack R, Kaushik D, Smith B, Stern F. Large-scale DES computations of the forward speed diffraction and pitch and heave problems for a surface combatant. Computers \& Fluids 2010;39:1095-111. doi:10.1016/j.compfluid.2010.02.002.

[22] Huang J, Carrica PM, Stern F. Semi-coupled air/water immersed boundary approach for curvilinear dynamic overset grids with application to ship hydrodynamics. International Journal for Numerical Methods in Fluids 2008;58:591-624. doi:10.1002/fld.1758.

[23] Carrica PM, Wilson RV, Stern F. An unsteady single-phase level set method for viscous free surface flows. International Journal for Numerical Methods in Fluids 2007;53:229-56. doi:10.1002/fld.1279.

[24] Carrica PM, Wilson RV, Noack RW, Stern F. Ship motions using single-phase level set with dynamic overset grids. Computers \& Fluids 2007;36:1415-33. doi:10.1016/j.compfluid.2007.01.007.

[25] Prescott WC. Numerical integration technique for multi-body dynamic system software. In: Symposium on international automotive technology, Pune; 1999.

[26] LMS International. Virtual.Lab Online Help Manual. 2013. 
[27] Jonkman JM, Butterfield S, Musial W, Scott G. Definition of a 5-MW reference wind turbine for offshore system development. NREL/TP-500-38060. National Renewable Energy Laboratory; 2009.

[28] Jonkman JM. Definition of the floating system for Phase IV of OC3. NREL/TP-500-47535. National Renewable Energy Laboratory; 2010. 


\section{Figure captions}

Figure 1 Wind turbine control system.

Figure 2 Drivetrain configuration.

Figure 3 Grid system. Surface grids shown in top panel, including details of the overset at blade tip and nacelle. Refinements and background dimensions are shown in lower panels.

Figure 4 Gear contact effect at uniform wind speed $8 \mathrm{~m} / \mathrm{s}$.

Figure 5 Gear contact effect on turbine performance at uniform wind $8 \mathrm{~m} / \mathrm{s}$.

Figure 6 Power spectrum density for effect of gear contact (case set 1).

Figure 7 Power spectrum density for effect of generator torque controller (case set 2).

Figure 8 Effect of blade pitch controller on turbine performance at wind speed $18 \mathrm{~m} / \mathrm{s}$.

Figure 9 Power spectrum density for effect of blade pitch controller (case set 3 ).

Figure 10 Blade tip deflections at wind speed $18 \mathrm{~m} / \mathrm{s}$.

Figure 11 Instantaneous non-dimensional axial velocity contour for flexible turbine at $\mathrm{z}=60 \mathrm{~m}$ and wind speed $18 \mathrm{~m} / \mathrm{s}$.

Figure 12 Average axial velocities at different axial positions and at $z=60 \mathrm{~m}$ for wind speed $18 \mathrm{~m} / \mathrm{s}$.

\section{List of tables}

Table 1 Drivetrain properties.

Table 2 CFD grid system for turbine simulations.

Table 3 Simulation matrix.

Table 4 Summary of wind turbine behavior with drivetrain dynamics. 


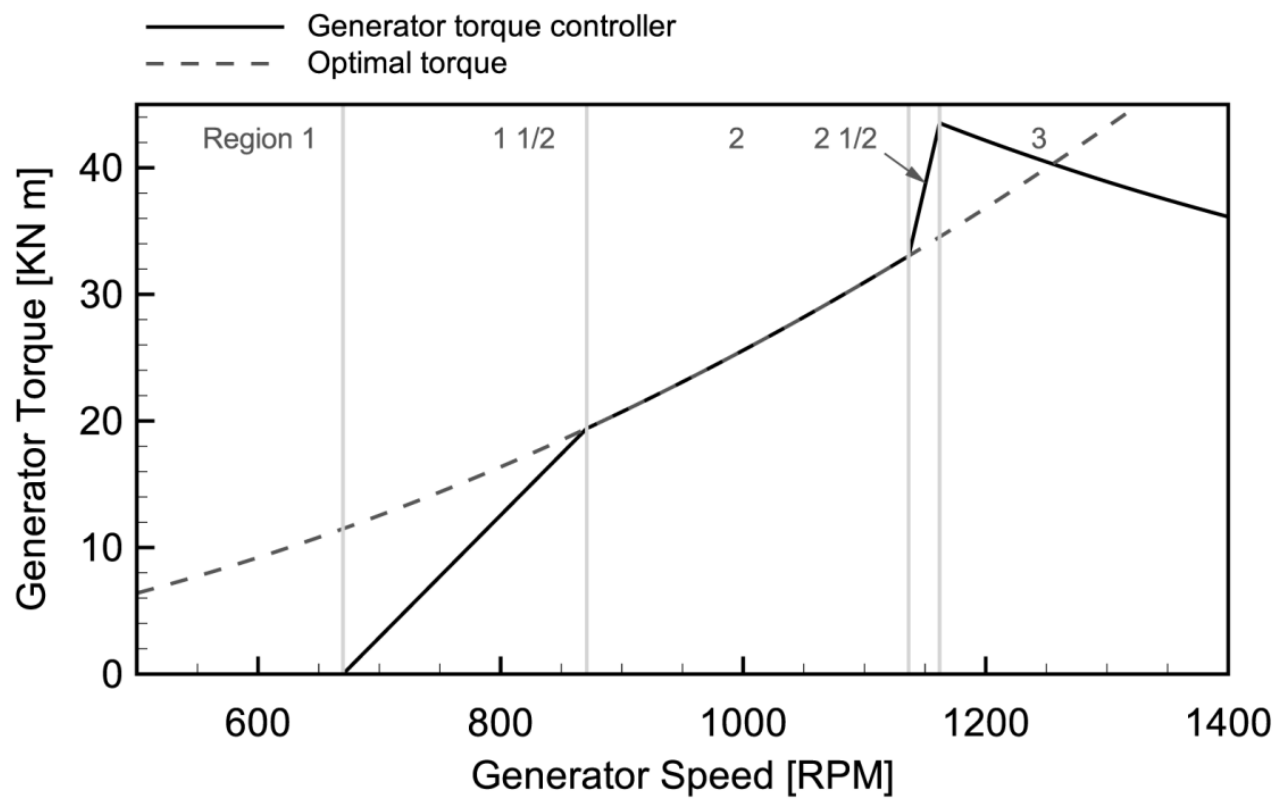

(a) Generator torque controller

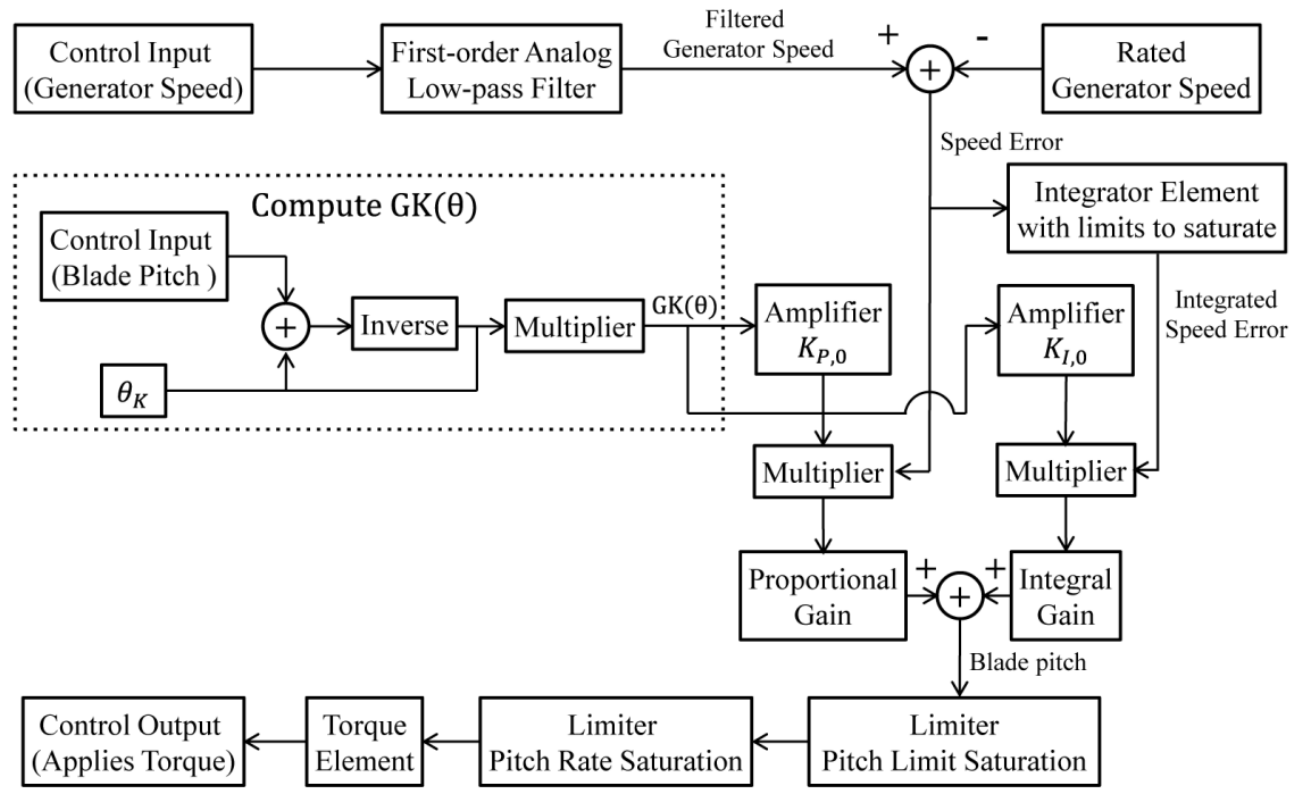

(b) Blade pitch controller

Figure 1 Wind turbine control system. 




Figure 2 Drivetrain configuration. 


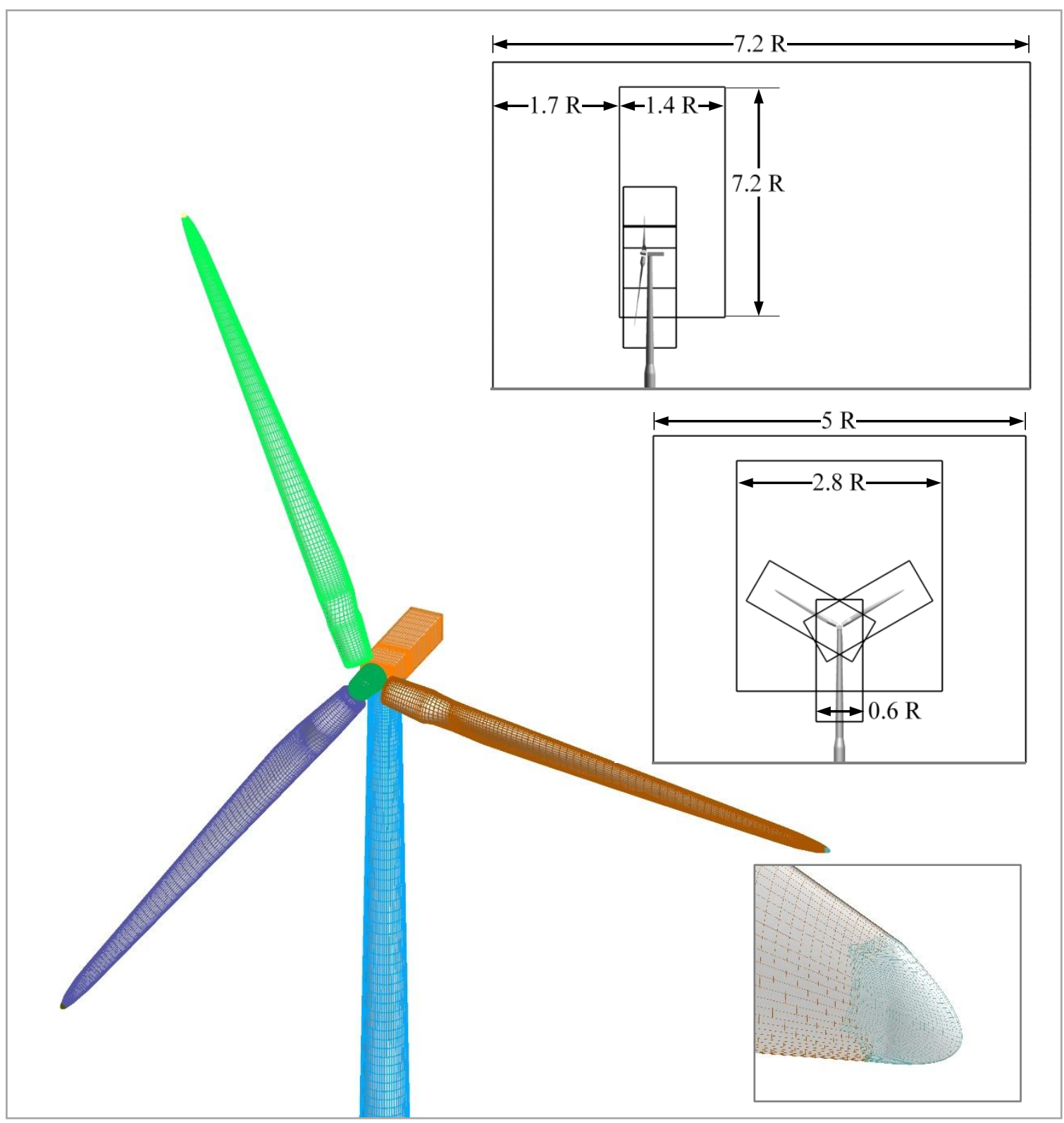

Figure 3 Grid system. Surface grids shown in top panel, including details of the overset at blade tip. Refinements and background dimensions are also shown. 

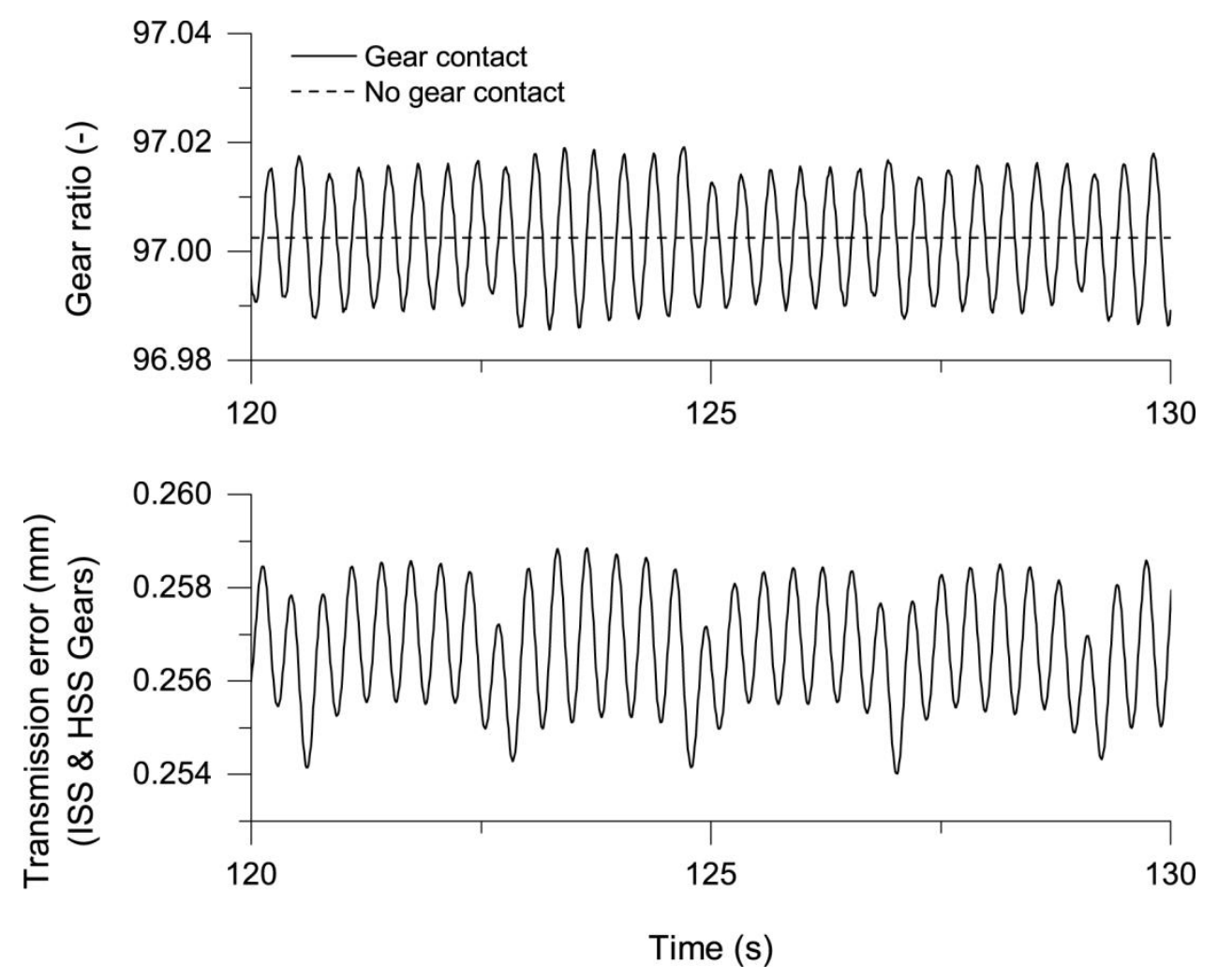

Figure 4 Gear contact effect at uniform wind speed $8 \mathrm{~m} / \mathrm{s}$. 

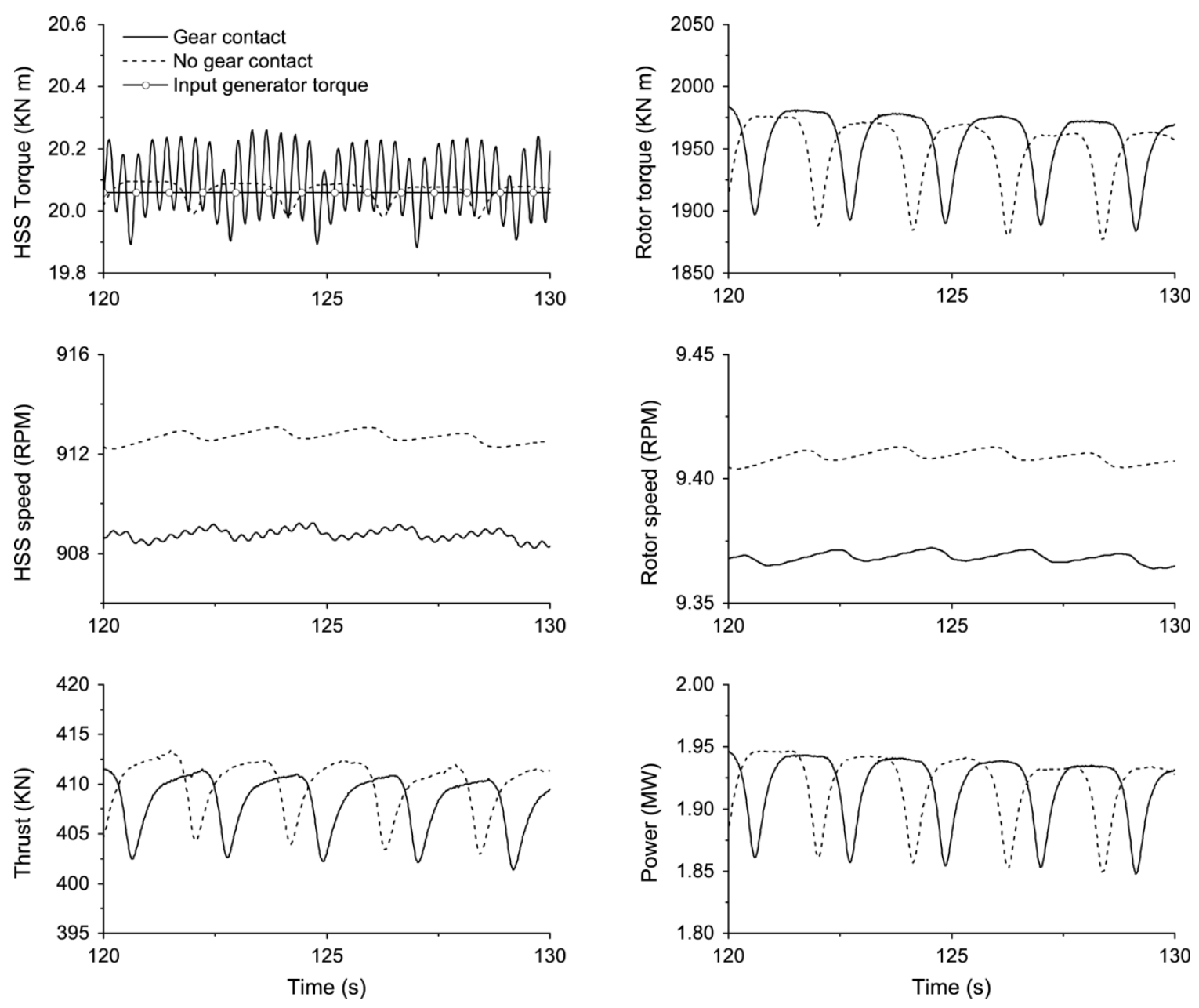

Figure 5 Gear contact effect on turbine performance at uniform wind $8 \mathrm{~m} / \mathrm{s}$. 

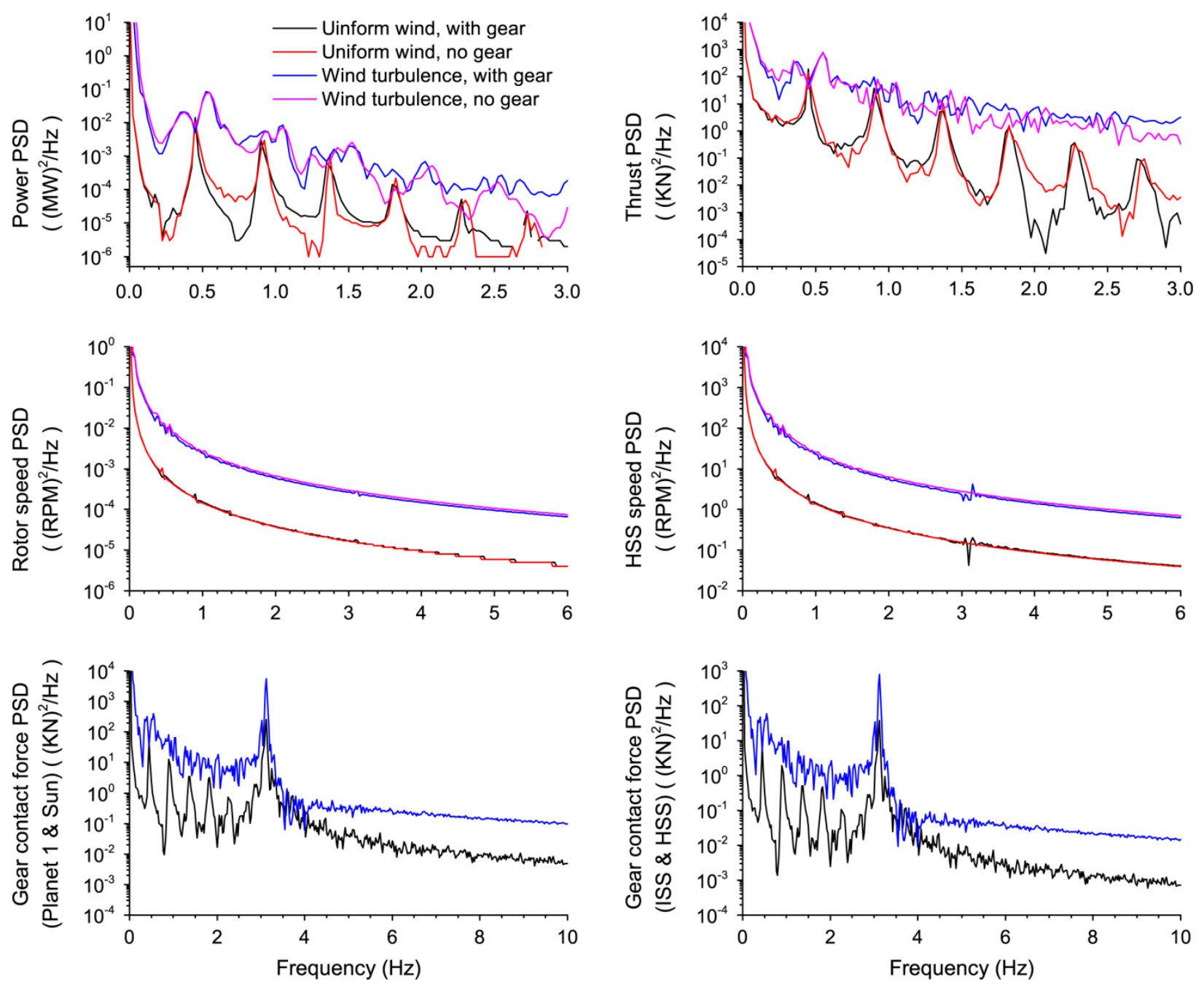

Figure 6 Power spectrum density for effect of gear contact (case set 1). 

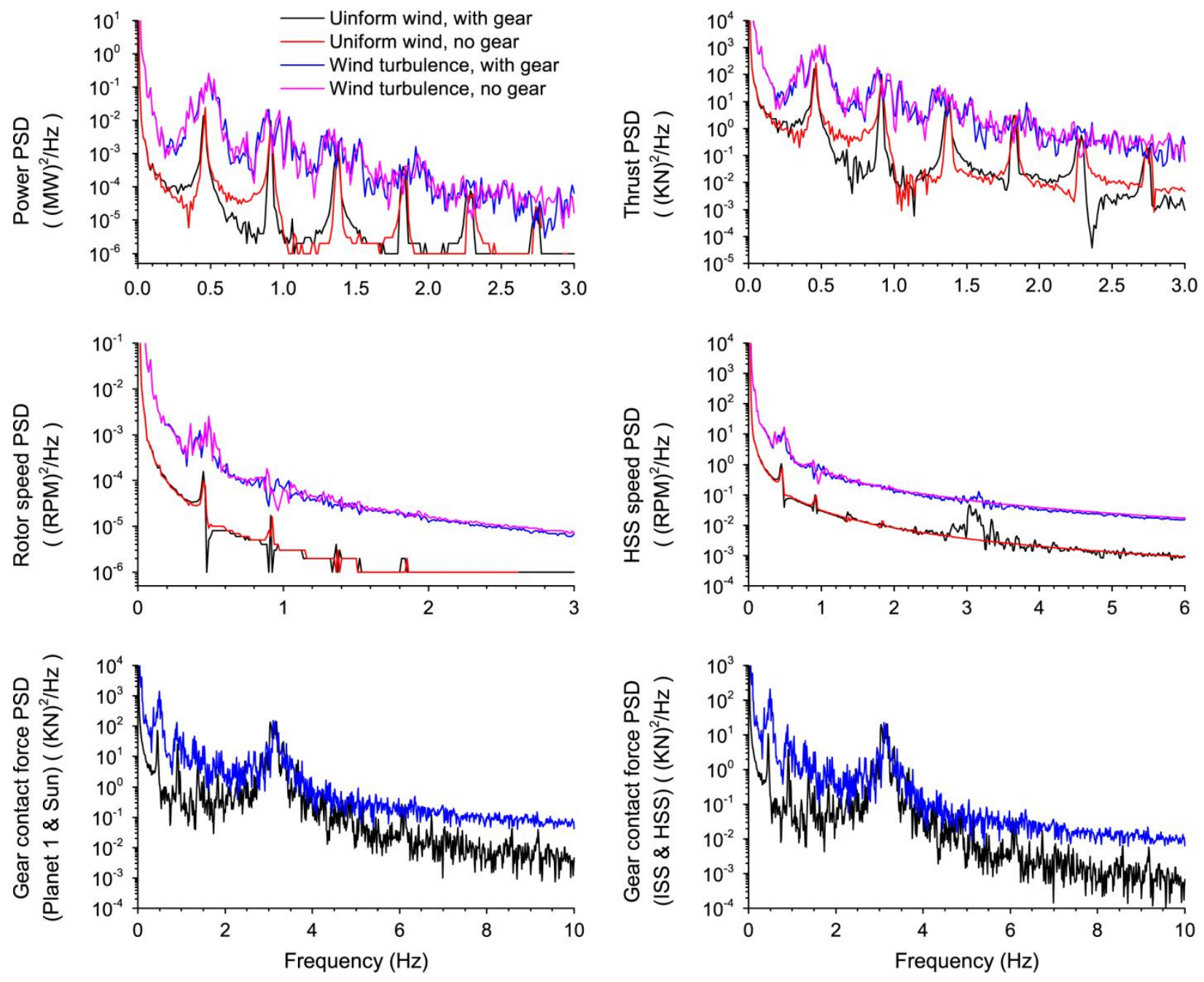

Figure 7 Power spectrum density for effect of generator torque controller (case set 2). 

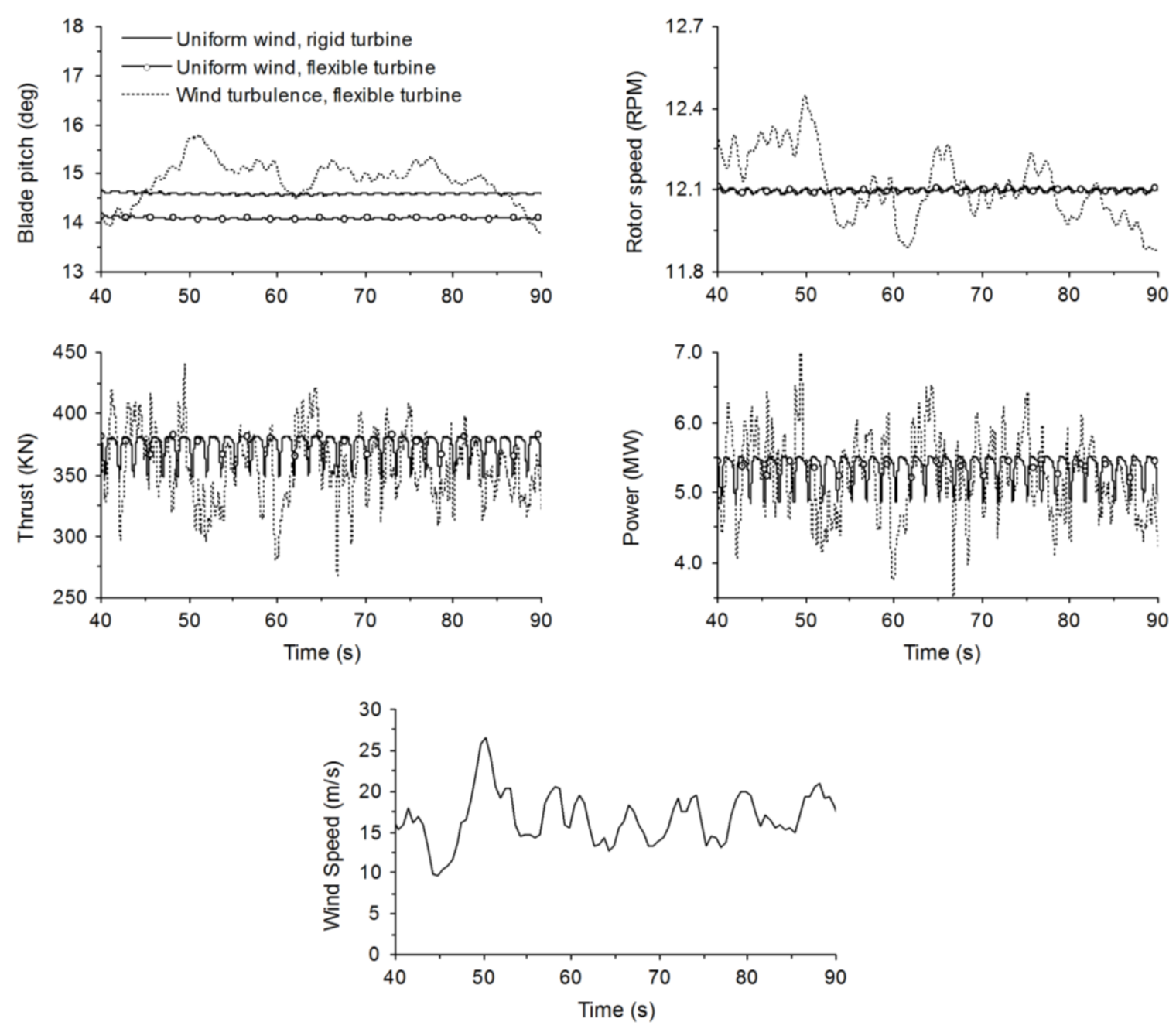

Figure 8 Effect of blade pitch controller on turbine performance at wind speed $18 \mathrm{~m} / \mathrm{s}$. Undisturbed wind speed predicted by Mann's model at hub height is also shown (ignoring presence of the turbine). 

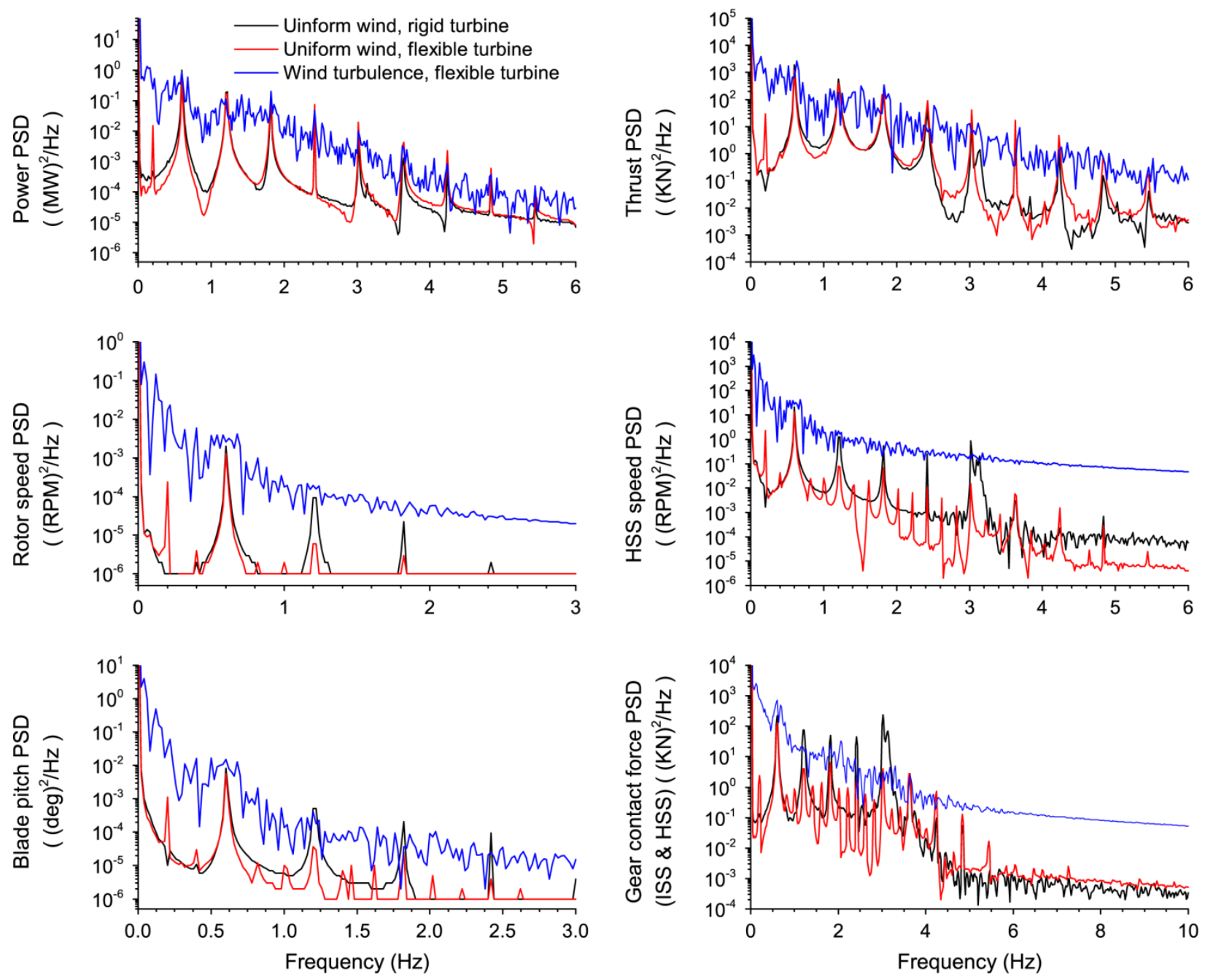

Figure 9 Power spectrum density for effect of blade pitch controller (case set 3). 

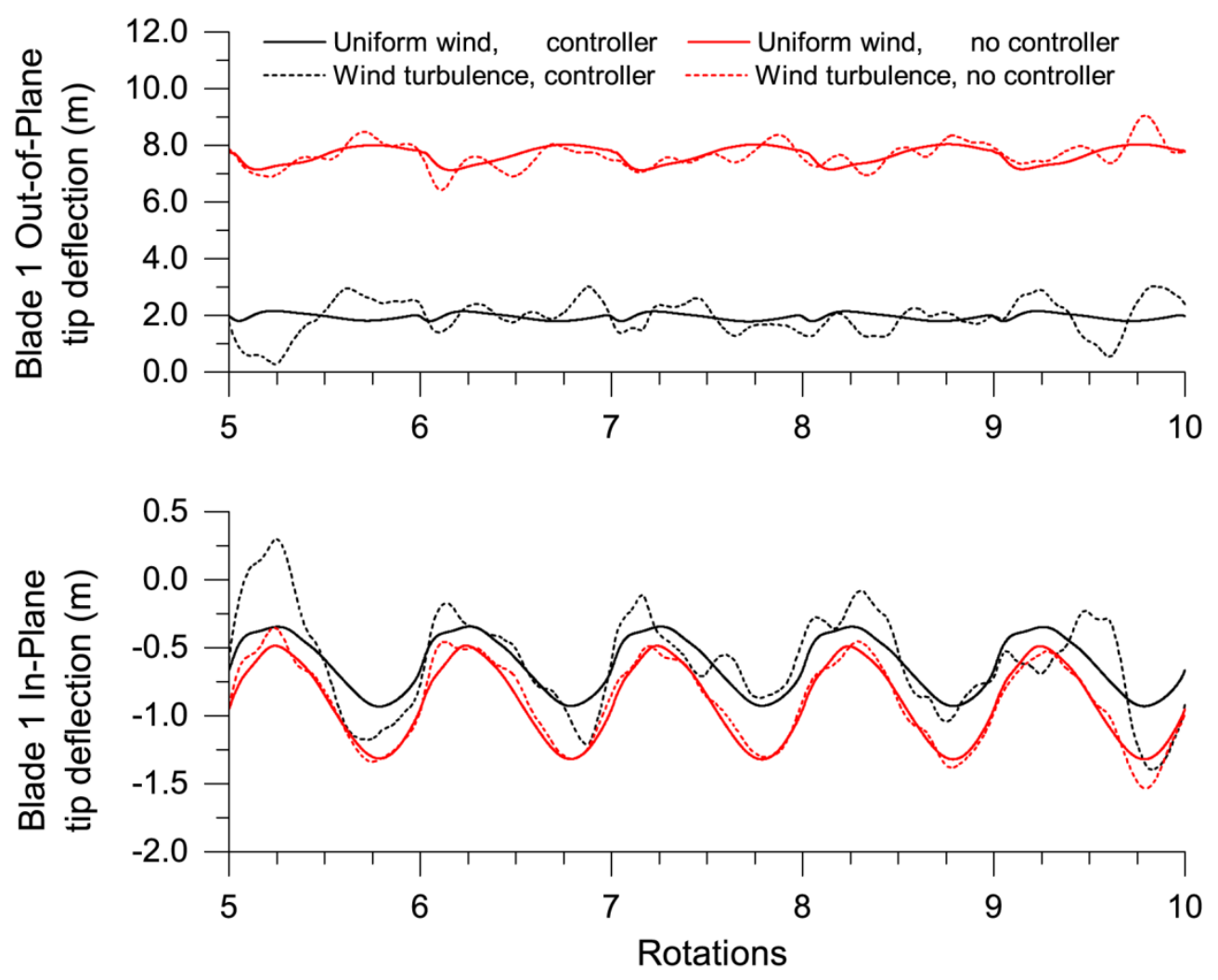

Figure 2 Blade tip deflections at wind speed $18 \mathrm{~m} / \mathrm{s}$. 


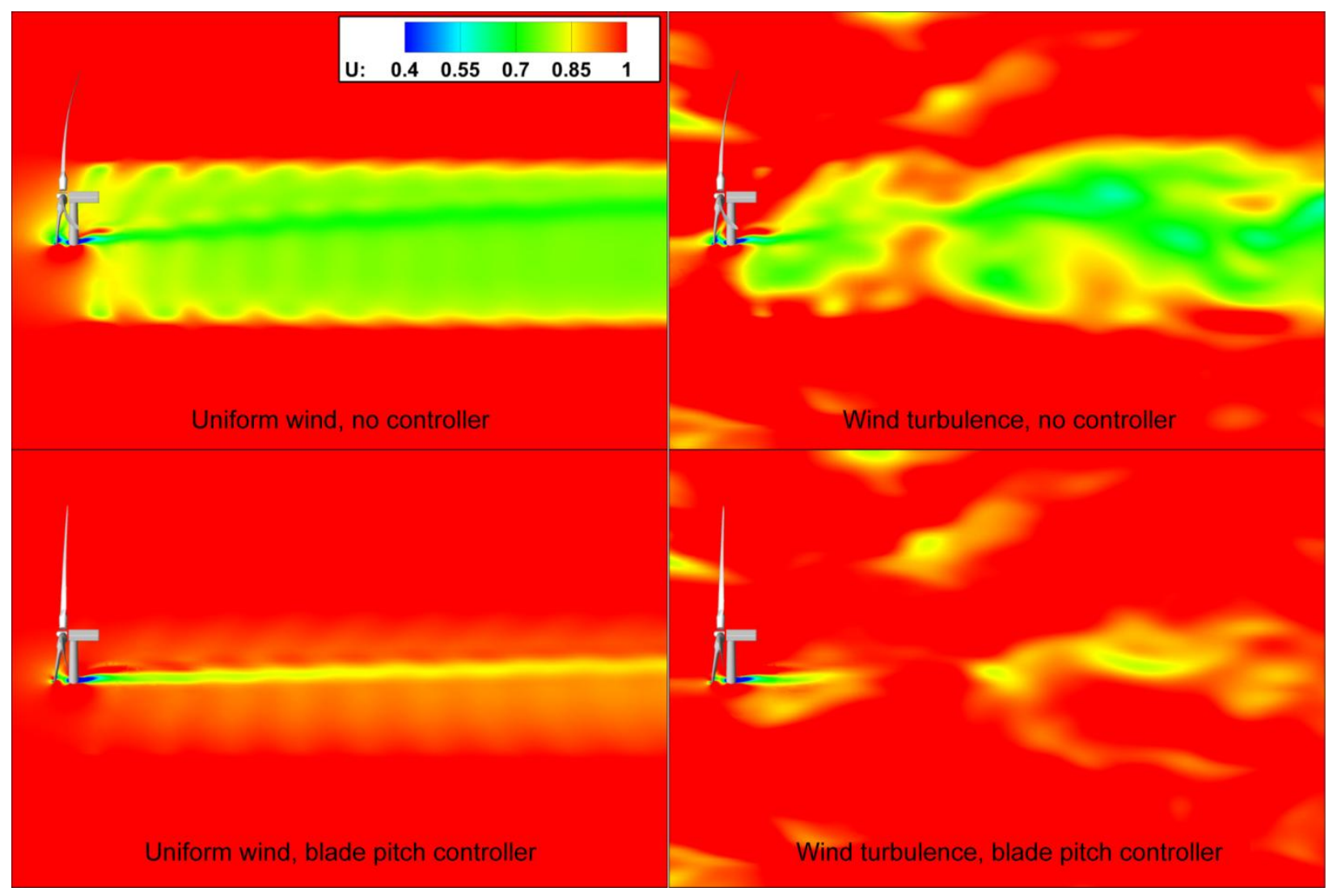

Figure 11 Instantaneous non-dimensional axial velocity contour for flexible turbine at $\mathrm{z}=60 \mathrm{~m}$ and wind speed $18 \mathrm{~m} / \mathrm{s}$. 


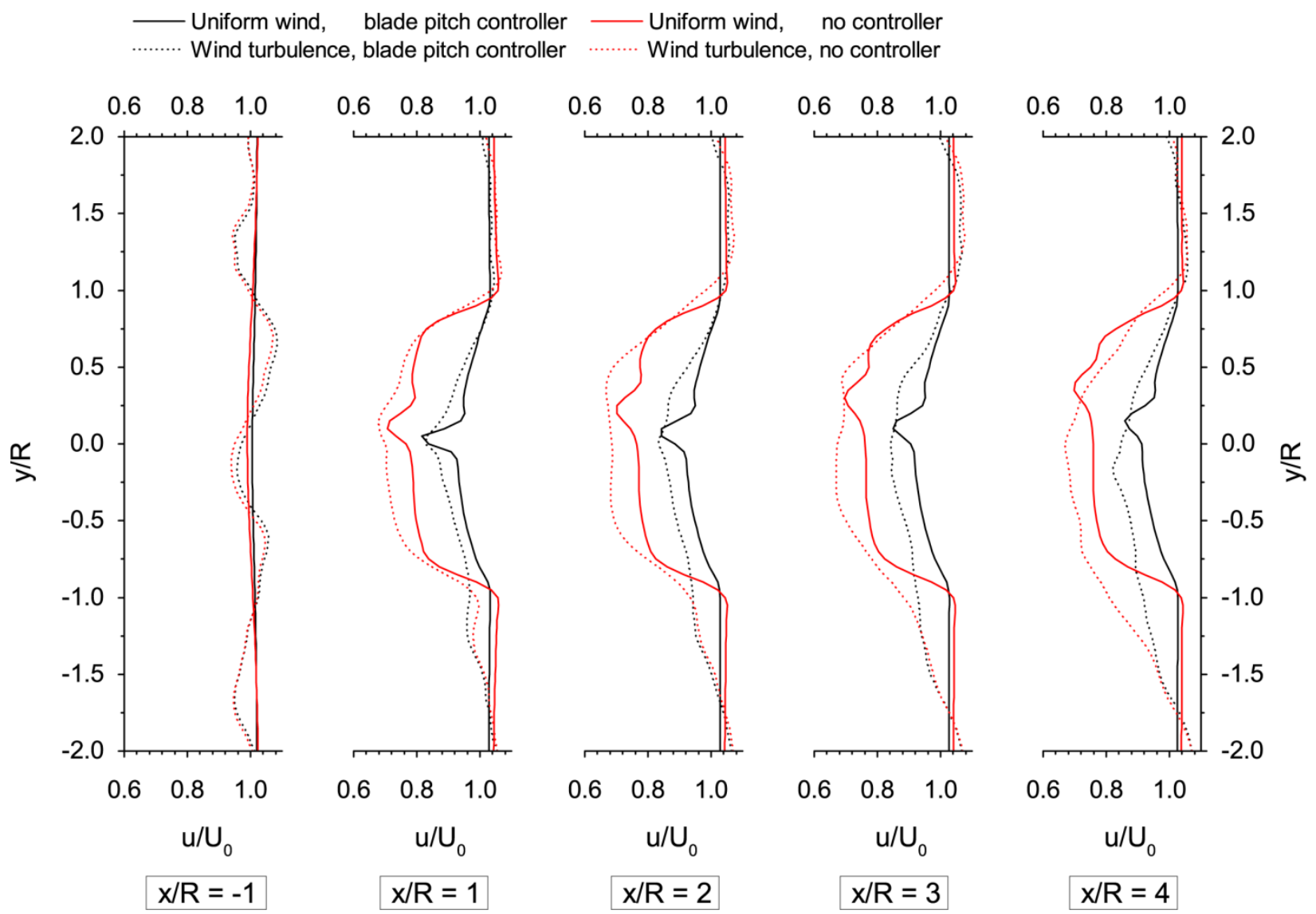

Figure 12 Average axial velocities at different axial positions and at $z=60 \mathrm{~m}$ for wind speed $18 \mathrm{~m} / \mathrm{s}$. 
Table 1 Drivetrain properties.

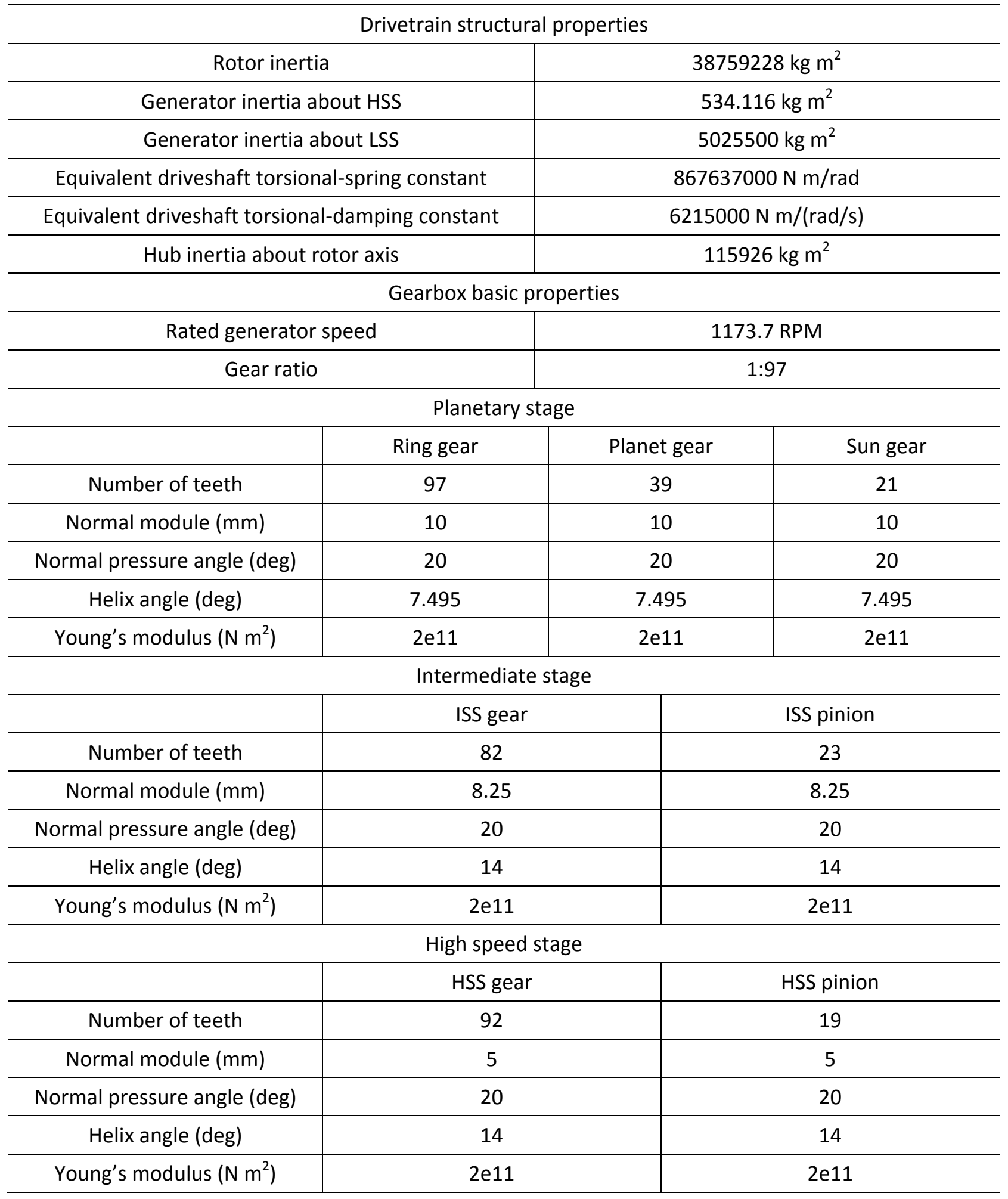


Table 2: CFD grid system for turbine simulations.

\begin{tabular}{ccc}
\hline Grid & Total points (K) & Type \\
\hline Tower & 589 & 0 \\
Nacelle & 149 & 0 \\
Hub & 149 & 0 \\
Blades & $3 \times 442$ & 0 \\
Tips & $3 \times 149$ & Wrapped \\
Blade Refinement & $3 \times 296$ & Cartesian \\
Wake Refinement & 149 & Cartesian \\
Background & 3031 & Cartesian \\
\hline Total & $6.728 \mathbf{M}$ & \\
\hline
\end{tabular}


Table 3 Simulation matrix.

\begin{tabular}{|c|c|c|c|c|c|c|}
\hline \multicolumn{2}{|c|}{ Case Set } & Wind Type & Mean Wind & $\begin{array}{l}\text { Blade } \\
\text { Flexibility }\end{array}$ & Gear Contact & Controller \\
\hline \multirow{4}{*}{1} & 1.1 & Uniform & \multirow{4}{*}{$8 \mathrm{~m} / \mathrm{s}$} & \multirow{4}{*}{ Rigid } & \multirow[b]{2}{*}{ No } & \multirow{4}{*}{ No } \\
\hline & 1.2 & $\begin{array}{c}\text { Turbulent } \\
\text { (Intensity 14\%) }\end{array}$ & & & & \\
\hline & 1.3 & Uniform & & & \multirow[b]{2}{*}{ Yes } & \\
\hline & 1.4 & $\begin{array}{c}\text { Turbulent } \\
\text { (Intensity 14\%) }\end{array}$ & & & & \\
\hline \multirow{4}{*}{2} & 2.1 & Uniform & \multirow{4}{*}{$8 \mathrm{~m} / \mathrm{s}$} & \multirow{4}{*}{ Rigid } & \multirow[b]{2}{*}{ No } & \multirow{4}{*}{$\begin{array}{c}\text { Generator } \\
\text { Torque }\end{array}$} \\
\hline & 2.2 & $\begin{array}{c}\text { Turbulent } \\
\text { (Intensity 14\%) }\end{array}$ & & & & \\
\hline & 2.3 & Uniform & & & \multirow[b]{2}{*}{ Yes } & \\
\hline & 2.4 & $\begin{array}{c}\text { Turbulent } \\
\text { (Intensity 14\%) }\end{array}$ & & & & \\
\hline \multirow{7}{*}{3} & 3.1 & Uniform & \multirow{7}{*}{$18 \mathrm{~m} / \mathrm{s}$} & Rigid & \multirow{7}{*}{ Yes } & \multirow{4}{*}{ No } \\
\hline & 3.2 & $\begin{array}{c}\text { Turbulent } \\
\text { (Intensity 14\%) }\end{array}$ & & Rigid & & \\
\hline & 3.3 & Uniform & & Flexible & & \\
\hline & 3.4 & $\begin{array}{c}\text { Turbulent } \\
\text { (Intensity 14\%) }\end{array}$ & & Flexible & & \\
\hline & 3.5 & Uniform & & Rigid & & \multirow{3}{*}{ Blade Pitch } \\
\hline & 3.6 & Uniform & & Flexible & & \\
\hline & 3.7 & $\begin{array}{c}\text { Turbulent } \\
\text { (Intensity 14\%) }\end{array}$ & & Flexible & & \\
\hline
\end{tabular}


Table 4 Summary of wind turbine behavior with drivetrain dynamics.

\begin{tabular}{|c|c|c|c|c|c|}
\hline \multicolumn{2}{|c|}{ Case Set } & Power (MW) & Thrust (kN) & Rotor Speed (RPM) & Blade Pitch (deg) \\
\hline \multirow{4}{*}{1} & 1.1 & $1.923 / 0.025$ & $410.01 / 2.59$ & $9.409 / 0.002$ & $0 / 0$ \\
\hline & 1.2 & $1.864 / 0.238$ & $420.31 / 27.85$ & $9.932 / 0.192$ & $0 / 0$ \\
\hline & 1.3 & $1.920 / 0.026$ & $408.38 / 2.72$ & $9.368 / 0.002$ & $0 / 0$ \\
\hline & 1.4 & $1.866 / 0.238$ & $417.60 / 27.91$ & $9.845 / 0.193$ & $0 / 0$ \\
\hline \multirow{4}{*}{2} & 2.1 & $1.920 / 0.026$ & $403.81 / 2.74$ & $9.225 / 0.005$ & $0 / 0$ \\
\hline & 2.2 & $1.942 / 0.373$ & $404.22 / 45.06$ & $9.262 / 0.397$ & $0 / 0$ \\
\hline & 2.3 & $1.919 / 0.027$ & $402.24 / 2.80$ & $9.178 / 0.005$ & $0 / 0$ \\
\hline & 2.4 & $1.942 / 0.372$ & $403.53 / 44.72$ & $9.223 / 0.390$ & $0 / 0$ \\
\hline \multirow{7}{*}{3} & 3.1 & $14.428 / 0.148$ & $1154.34 / 4.31$ & $12.1 / 0$ & $0 / 0$ \\
\hline & 3.2 & $14.260 / 0.954$ & $1144.10 / 34.89$ & $12.1 / 0$ & $0 / 0$ \\
\hline & 3.3 & $11.930 / 0.140$ & $1097.53 / 5.71$ & $12.1 / 0$ & $0 / 0$ \\
\hline & 3.4 & $11.904 / 0.730$ & $1097.41 / 36.92$ & $12.1 / 0$ & $0 / 0$ \\
\hline & 3.5 & $5.361 / 0.194$ & $374.22 / 9.89$ & $12.099 / 0.008$ & $14.596 / 0.021$ \\
\hline & 3.6 & $5.331 / 0.162$ & $375.75 / 8.50$ & $12.099 / 0.006$ & $14.098 / 0.018$ \\
\hline & 3.7 & $5.231 / 0.580$ & $357.04 / 28.39$ & $12.112 / 0.127$ & $14.882 / 0.414$ \\
\hline
\end{tabular}

